Check for updates

Cite this: Metallomics, 2020, 12,1246

Received 26th March 2020, Accepted 1st June 2020

DOI: 10.1039/d0mt00080a

rsc.li/metallomics

\section{Laser ablation-ICP-TOFMS imaging of germ cell tumors of patients undergoing platinum-based chemotherapy $\dagger$}

\author{
Sarah Theiner, (D) *a Andreas Schweikert, ${ }^{\text {ab }}$ Christine Haberler, $^{c}$ Andreas Peyrl ${ }^{d}$ and \\ Gunda Koellensperger ${ }^{a}$
}

\begin{abstract}
A low dispersion laser ablation setup in combination with inductively coupled plasma-time-of-flight mass spectrometry (LA-ICP-TOFMS) was applied to clinical samples of patients undergoing platinum-based chemotherapy. The platinum accumulation together with the distribution of elements with biological key functions (Mg, P, S, Ca, Fe, Cu and Zn) was studied in central nervous system germ cell tumor (CNS GCT) tissue, which is an aggressive tumor type located in the brain. Heterogeneous elemental distribution patterns were obtained with a pixel size of $10 \mu \mathrm{m}$ and were correlated to histological analysis of serial sections using hematoxylin eosin staining. Highest platinum accumulation correlated with areas of necrosis, which exhibited high levels of magnesium, sulphur and calcium. Small traces of gadolinium were found in the tumor sections, which is a result of prior magnetic resonance imaging. Iron accumulated in regions, which were dense in blood vessels, whereas areas with fibrosis scar showed the lowest levels of all detected elements. This LA-ICPTOFMS study demonstrates that the chemotherapeutic drug cisplatin accumulated in the germ cell tumor located in the brain, which is also reflected by the therapy response of the patients.
\end{abstract}

Significance to metallomics

This work highlights the potential of laser ablation in combination with inductively coupled plasma-time-of-flight-mass spectrometry for the analysis of tumor samples of patients undergoing cisplatin-based chemotherapy. A clear platinum accumulation in tumor tissue was observed in central nervous system germ cell tumor, an aggressive tumor type that is located in the brain. LA-ICP-TOFMS results reflect observations made by clinical histological screening methods as endogenous elemental distribution patterns correlate well with the underlying histology of the tumor tissue.

\section{Introduction}

Central nervous system germ cell tumors (CNS GCTs) encompass a wide histologic spectrum and are most commonly located in the pineal and suprasellar regions of the brain. ${ }^{1}$ For secreting GCTs, multimodal treatment strategies are used that involve a combination of chemotherapy and radiation. For patients that do not obtain a complete radiographic response after chemotherapy, a second-look surgery is performed. Platinum-based antineo-

\footnotetext{
${ }^{a}$ Institute of Analytical Chemistry, University of Vienna, Waehringer Strasse 38, 1090 Vienna, Austria. E-mail: sarah.theiner@univie.ac.at; Tel: +431427752383

${ }^{b}$ Institute of Inorganic Chemistry, University of Vienna, Waehringer Strasse 42, 1090 Vienna, Austria

${ }^{c}$ Clinical Institute of Neurology, Medical University of Vienna,

Waehringer Guertel 18-20, 1090 Vienna, Austria

${ }^{d}$ Department of Pediatrics and Adolescent Medicine, Medical University of Vienna, Waehringer Guertel 18-20, 1090 Vienna, Austria

$\dagger$ Electronic supplementary information (ESI) available. See DOI: 10.1039/d0mt00080a
}

plastic agents (cisplatin, carboplatin and oxaliplatin) are pivotal in the treatment of a variety of tumors of different histology, including germ cell tumors. ${ }^{2}$ The size, hydrophobic character and tendency to bind to proteins of the clinically used platinum(II)based anticancer drugs might limit their ability to cross the intact blood-brain barrier (BBB) and compromise their efficacy for the treatment of tumors located in the brain. The presence of cancerous tissue in the central nervous system and prior radiation therapy can compromise the BBB and allow the diffusion of chemotherapeutics. ${ }^{3}$ An important factor to assess therapeutic response to chemotherapy is an understanding of the drug distribution within the tumor tissue relative to histologic structure. Laser ablation-inductively coupled plasma mass spectrometry (LA-ICPMS) has become an established technique in the field of bioimaging, providing insights into the multi-element distribution in biological samples with high sensitivity and at high-resolution at the low $\mu \mathrm{m}$ scale. ${ }^{4,5}$ The distribution of administered pharmaceutical agents such as cisplatin has been studied by LA-ICPMS in 
target and non-target tissues providing information on depth of tissue penetration, metabolic fate and adverse side effects. ${ }^{6}$ Several LA-ICPMS studies have focused on kidney to investigate the nephrotoxic effects of cisplatin chemotherapy. ${ }^{7-10}$ On the preclinical level, multicellular tumor spheroids have been used as in vitro model systems to study metallodrug uptake by LA-ICPMS due to their tissue-like structure and three-dimensional cell organisation/ interaction. ${ }^{11,12}$ For the evaluation of drug candidates in animal experiments in comparison to clinically established drugs, LA-ICPMS protocols have been developed to investigate the platinum distribution in murine tumor and organ samples of different cancer types upon treatment with platinum(II) drugs, ${ }^{13,14}$ platinum(Iv) agents, ${ }^{15}$ ruthenium and osmium compounds, ${ }^{10,16}$ undergoing preclinical and clinical evaluation. On patient samples, LA-ICPMS was used to study e.g. the extravasation of cisplatin, ${ }^{17}$ and the uptake of cisplatin in mesothelioma tumor samples. ${ }^{18,19}$

In the majority of bioimaging studies, LA-ICPMS has been used as a research technique. For applications where the technology is proposed as a clinical or diagnostic tool, throughput and high spatial resolution becomes paramount. With the recent advancements in the development of low dispersion laser ablation setups, high-resolution mapping at the cellular level and at increased speed with higher sensitivity compared to conventional laser ablation systems has become feasible. ${ }^{20}$ The settling time of sequential scanning type ICP-MS (quadrupole or sector-field mass analyzers), which can vary between $0.01-0.5 \mathrm{~ms}$, limits their ability to monitor multiple nuclides during signal pulses delivered by low dispersion LA systems. To obtain multi-element information, ICP-MS instruments equipped with time-of-flight mass analyzers are the instruments of choice as they provide the required simultaneous analysis of a wide range of elements of the entire mass range and fast data read-out. ${ }^{21}$ The CyTOF ICP-MS TOF-based equipment has been specifically targeted towards applications relevant in the clinical field for the multi-parametric analysis of biomarkers in cells and tissue sections. ${ }^{22}$ The concept of imaging mass cytometry makes use of the indirect detection of target analytes by metal-conjugated antibodies at (sub-)cellular resolution in tissue sections in the mass range $m / z=75-209 .^{23,24}$ Main applications include the field of immunology, oncology and pharmaceutical research. ${ }^{25}$

In a previous study, we described the use of a low dispersion laser ablation setup in combination with ICP-TOFMS detection for single cell multi-element profiling and cisplatin uptake of individual blood cells derived from patients undergoing cisplatin-based chemotherapy. ${ }^{26}$ In this work, we demonstrate the potential of LA-ICP-TOFMS to investigate the distribution of platinum together with the multi-element pattern in central nervous system germ cell tumors from patients undergoing platinum-based chemotherapy in correlation with the underlying histology.

\section{Experimental}

\section{Patient details and sample preparation}

A 22-year old male patient (patient 1) was diagnosed with a recurrence of a malignant secreting germ cell tumor. He received four cycles of chemotherapy, including cisplatin with a cumulative dose of $300 \mathrm{mg} \mathrm{m}^{-2}$ and carboplatin with a cumulative dose of $1600 \mathrm{mg} \mathrm{m}^{-2}$ before the resection of visible remaining parts of the tumor and subsequent radiotherapy. Three weeks prior the operation he received cisplatin at a total dose of $100 \mathrm{mg} \mathrm{m}^{-2}$. A 13-year old male patient (patient 2) was diagnosed with a malignant secreting germ cell tumor. He received four cycles of chemotherapy, including cisplatin with a cumulative dose of $400 \mathrm{mg} \mathrm{m}^{-2}$ before resection of visible remaining parts of the tumor and subsequent radiotherapy. Three weeks prior the operation he received cisplatin at a total dose of $100 \mathrm{mg} \mathrm{m}^{-2}$. An 18-year old male patient (patient 3) was diagnosed with a suprasellar tumor and consecutive hydrocephalus. The intracranial pressure was relieved in an emergency operation. Histology revealed mixed germ cell tumor and as consequence, he received four cycles of chemotherapy and subsequent radiotherapy. Prior to the operation he did not receive any chemotherapy and therefore the sample was used as a control sample. To date, all three patients are in complete remission after intensive therapy. All experiments were performed in compliance with the relevant laws and institutional guidelines. The study was approved by the Ethics Committee of the Medical University of Vienna (EK 1244/2016). Informed consent was obtained for the use of the tumor sections of the patients.

Sample preparation for LA-ICPMS and histological analysis was based on the clinical routine practice of formalin fixation followed by paraffin-embedding (FFPE). Briefly, tumors were fixed in $4 \%$ formaldehyde for $24 \mathrm{~h}$ and embedded in paraffin blocks. Consecutive paraffin-embedded sections were cut into $5 \mu \mathrm{m}$ thickness, placed onto glass slides and air-dried. One consecutive section to the sections used for laser ablation analysis was used for hematoxylin eosin (HE) staining. Two tumor sections were analyzed by LA-ICPMS for patient 1 and 2, respectively and one tumor section was analyzed for patient 3 (control).

\section{LA-ICP-TOFMS imaging}

An Analyte Excite $193 \mathrm{~nm}$ ArF$^{*}$ excimer-based laser ablation system (Teledyne Photon Machines, Bozeman, MT, U.S.A.) was coupled to an icpTOF 2R (TOFWERK AG, Thun, Switzerland) TOF-based ICP-MS instrument. The laser ablation system was equipped with the HelEx II 2-volume ablation cell and the aerosol rapid introduction system (ARIS). The mixing bulb of the ARIS was used to introduce an Ar make-up gas flow $\left(\sim 1.10 \mathrm{~L} \mathrm{~min}^{-1}\right)$ into an optimized He carrier gas flow of $0.60 \mathrm{~L} \min ^{-1}$ before entering the plasma. The laser ablation and ICP-TOFMS settings were optimized at the start of each experiment while ablating NIST SRM612 glass certified reference material (National Institute for Standards and Technology, Gaithersburg, MD, U.S.A.). Optimization was based on high intensities for ${ }^{24} \mathrm{Mg}^{+},{ }^{89} \mathrm{Y}^{+},{ }^{115} \mathrm{In}^{+}$and ${ }^{238} \mathrm{U}^{+}$, low oxide formation based on the ${ }^{238} \mathrm{U}^{16} \mathrm{O}^{+} /{ }^{238} \mathrm{U}^{+}$ratio $(<2 \%)$ and low laser-induced elemental fractionation based on the ${ }^{238} \mathrm{U}^{+} /{ }^{232} \mathrm{Th}^{+}$ratio $(\sim 1)$. Laser ablation sampling was performed in fixed dosage mode 2 , at a repetition rate of $25-30 \mathrm{~Hz}$ and using a square spot size of $20 \mu \mathrm{m}$. The line scans overlapped one another by $10 \mu \mathrm{m}$ in 
$y$-direction. The laser parameters used resulted in a pixel size of $10 \mu \mathrm{m}$. Tumor tissue was removed quantitatively using a fluence of $1-1.5 \mathrm{~J} \mathrm{~cm}^{-2}$.

The icpTOF 2R ICP-TOFMS instrument has a specified mass resolution $(R=m / \Delta m)$ of 6000 (FWHM definition). The standard operation mode was used which balances mass resolving power, sensitivity and ion transmission across the entire measured mass range and which allows the analysis of ions from $m / z=14-254$. The integration and read-out rate match the laser ablation repetition rate. The instrument was equipped with a torch injector of $2.5 \mathrm{~mm}$ inner diameter and nickel sample and skimmer cones with a skimmer cone insert of $2.8 \mathrm{~mm}$ in diameter. A radio frequency power of $1400 \mathrm{~W}$, an auxiliary $\mathrm{Ar}$ gas flow rate of $\sim 0.90 \mathrm{~L} \mathrm{~min}^{-1}$ and a plasma Ar gas flow rate of $15 \mathrm{~L} \mathrm{~min}^{-1}$ was used.

\section{Data acquisition and processing}

Data was recorded using TofPilot 1.3.0.0 (TOFWERK AG, Thun, Switzerland). ICP-TOFMS data was saved in the open-source hierarchical data format (HDF5, www.hdfgroup.org). Postacquisition data processing was performed with Tofware, which is a TOFWERK data analysis package and used as an add-on on IgorPro (Wavemetric Inc., Oregon, U.S.A.). Data processing comprised the following steps: (1) drift correction of the mass peak position in the spectra over time via time-dependent mass calibration (2) determining the peak shape (3) fitting and subtracting the mass spectral base-line and (4) calculating high-resolution peak fits for peak deconvolution. LA-ICPTOFMS data was further processed with HDIP version 1.3.1. (Teledyne Photon Machines, Bozeman, MT, U.S.A.). Elemental intensity maps were generated and results are given as ions per extraction for all isotopes.

\section{Results and discussion}

Multi-element imaging of central nervous system germ cell tumor tissue sections of two patients undergoing platinumbased chemotherapy was performed using a state-of-the-art laser ablation setup in combination with ICP-TOFMS detection. Sample preparation was based on routine clinical practice of formalin-fixation followed by paraffin-embedding (FFPE) and unstained tumor sections of $5 \mu \mathrm{m}$ thickness were used for analysis. Elemental distribution patterns were compared to the underlying histology of the tumor sections using a hematoxylin eosin (HE) stained tumor section of an adjacent slide.

\section{Multi-element distribution in germ cell tumor tissue}

Both patients received four cycles of chemotherapy with the last administration of cisplatin three weeks prior to surgery. Levels of platinum were still high enough to be detected by LA-ICPTOFMS three weeks after the last chemotherapy cycle. Platinum accumulation was observed throughout the entire tumor sections of both patients undergoing platinum-based chemotherapy (Fig. 1). The platinum distribution pattern was heterogeneous in all analyzed tissue sections with a difference in platinum concentrations of more than one order of magnitude within the tissue. Cisplatin might be present in the analyzed germ cell tumor sections bound to proteins and/or DNA. The tumor section of patient 3 was used as a 'control sample', as patient 3 received no platinum-based chemotherapy prior to the operation. No platinum was found in the tumor section (results not shown).

Another exogenously introduced element that was found in the tumor sections of all three patients is gadolinium (Fig. $2 \mathrm{H}$ and Fig. S1G, S2C, S4B, ESI $\dagger$ ), which is a result of a gadolinium-based
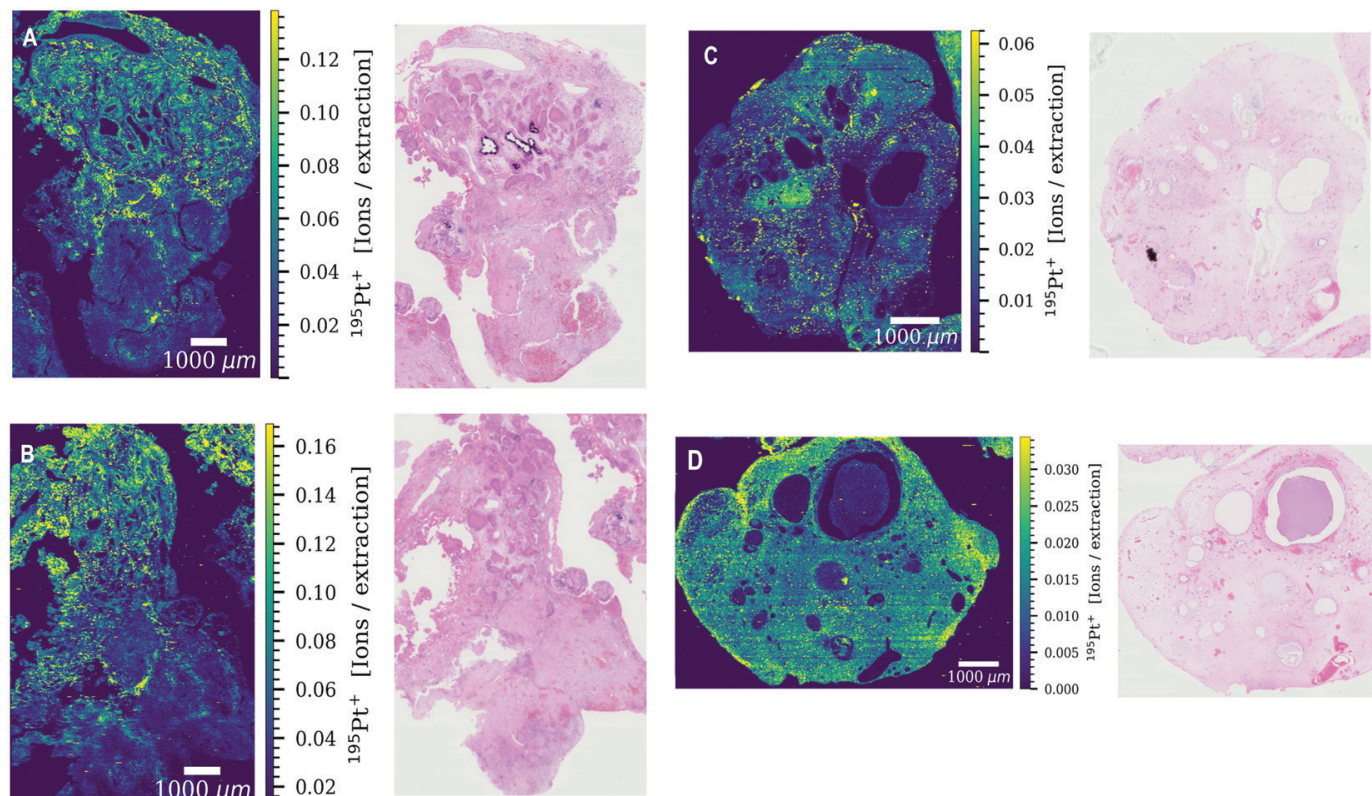
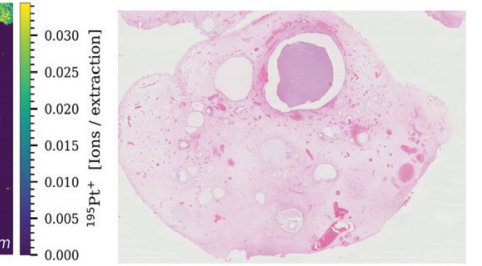

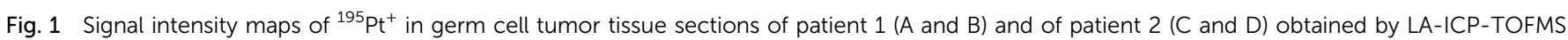

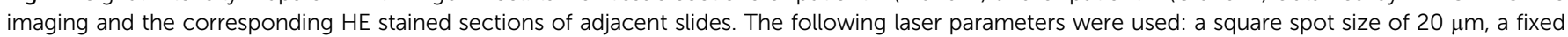
dosage mode of 2 and a repetition rate of $30 \mathrm{~Hz}$. Parallel line scans overlapped one another by $10 \mu \mathrm{m}$. 
contrast agent administered to the patients for magnetic resonance imaging (MRI). The toxic effect of the accumulation of gadolinium-based contrast agents in the brain and its excretion is still under debate. ${ }^{27}$ In addition to gadolinium and platinum, a variety of elements with biological key functions (magnesium, phosphorus, sulphur, calcium, iron, copper and zinc) was detected by LA-ICP-TOFMS in the germ cell tumor tissue sections of the two patients (Fig. 2 and Fig. S1, S2, ESI $\dagger$ ). Endogenous elements such as phosphorus and sulphur can be used to visualize the tumor tissue structure (Fig. 2B and C) without the need for additional staining reagents or labelling approaches. In the CyTOF technology, antibodies labelled with metals mostly from the lanthanide series are detected in tissue samples by LA-ICP-TOFMS. The mass range of the CyTOF instrument is however currently limited to masses over $75 \mathrm{Da}$ and therefore counterstaining procedures such as the use of $\mathrm{OsO}_{4}$ or $\mathrm{RuO}_{4}$ are required to visualize the overall tissue structure. ${ }^{28,29}$ With the ICPTOFMS instrument used for this study, endogenous elements that are constituents of proteins, lipids or the DNA can be detected and can be used for this purpose. In order to rule out artifacts, the levels/distributions of different endogenous elements can be used for tissue visualization.

\section{Correlation of the multi-element distribution in germ cell tumor tissue with the histology}

The elements determined by LA-ICP-TOFMS follow a heterogeneous distribution pattern in the germ cell tumor tissue, which was correlated with the underlying histology using a hematoxylin eosin (HE) stained germ cell tumor section of an adjacent slide. The germ cell tumor sample of patient 1 is composed of unspecific tissue. Enhanced platinum accumulation was found in areas of necrosis, which also showed enrichment of magnesium, sulphur and calcium levels (Fig. 3C-G), but no visible accumulation of iron (Fig. 3B). An overlay of platinum and iron intensity maps shows a reverse correlation of these two elements in the tumor section of patient 1 (Fig. 3B).
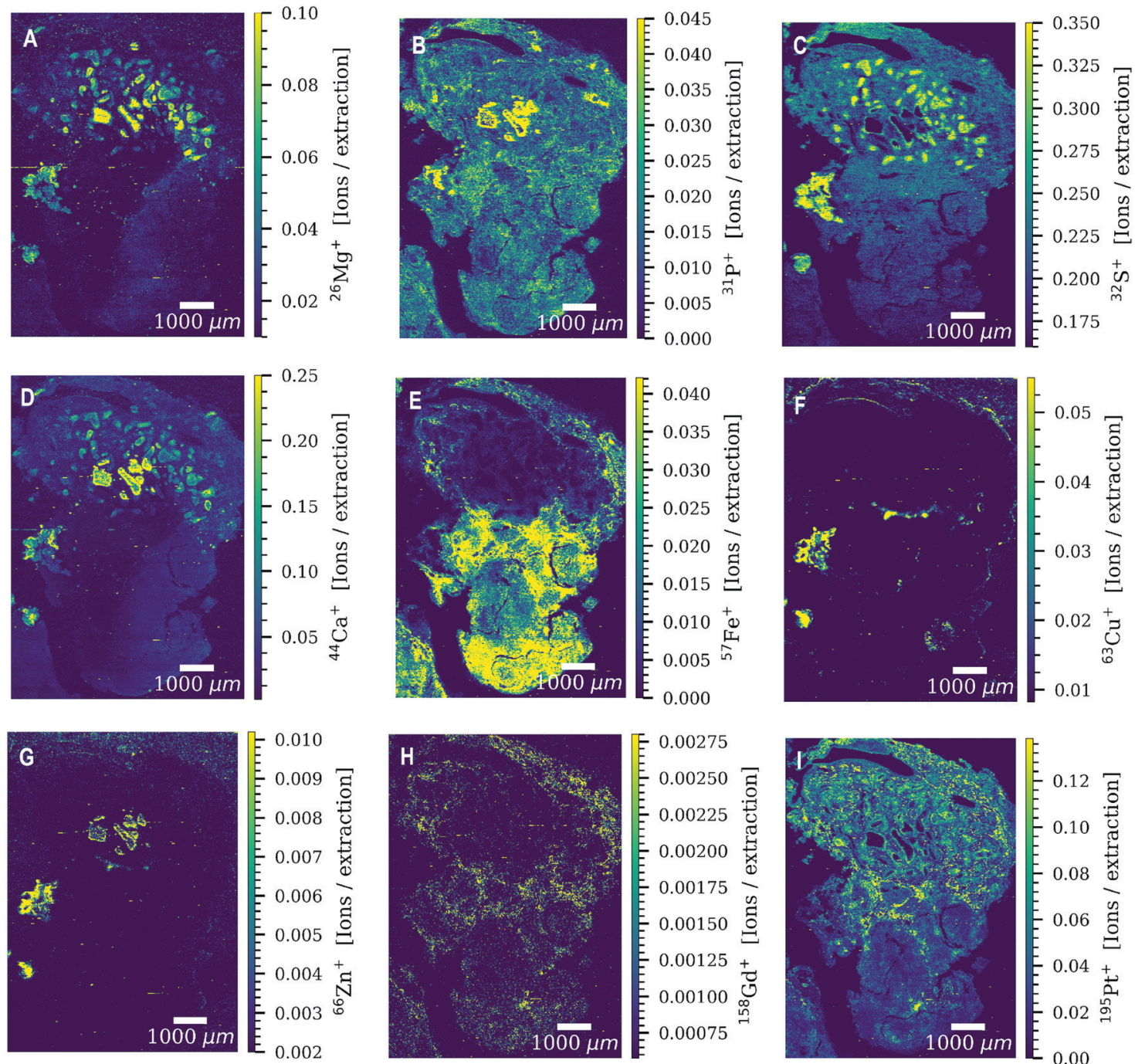

Fig. 2 Signal intensity maps of (A) ${ }^{26} \mathrm{Mg}^{+},(\mathrm{B}){ }^{31} \mathrm{P}^{+},(\mathrm{C}){ }^{32} \mathrm{~S}^{+},(\mathrm{D}){ }^{44} \mathrm{Ca}^{+},(\mathrm{E}){ }^{57} \mathrm{Fe}^{+},(\mathrm{F}){ }^{63} \mathrm{Cu}^{+},(\mathrm{G}){ }^{66} \mathrm{Zn}^{+},(\mathrm{H}){ }^{158} \mathrm{Gd}^{+}$and (I) ${ }^{195} \mathrm{Pt}^{+}$in a germ cell tumor tissue section of patient 1 obtained by LA-ICP-TOFMS imaging. The following laser parameters were used: a square spot size of $20 \mu \mathrm{m}$, fixed dosage mode of 2 and a repetition rate of $30 \mathrm{~Hz}$. The parallel line scans overlapped one another by $10 \mu \mathrm{m}$. 

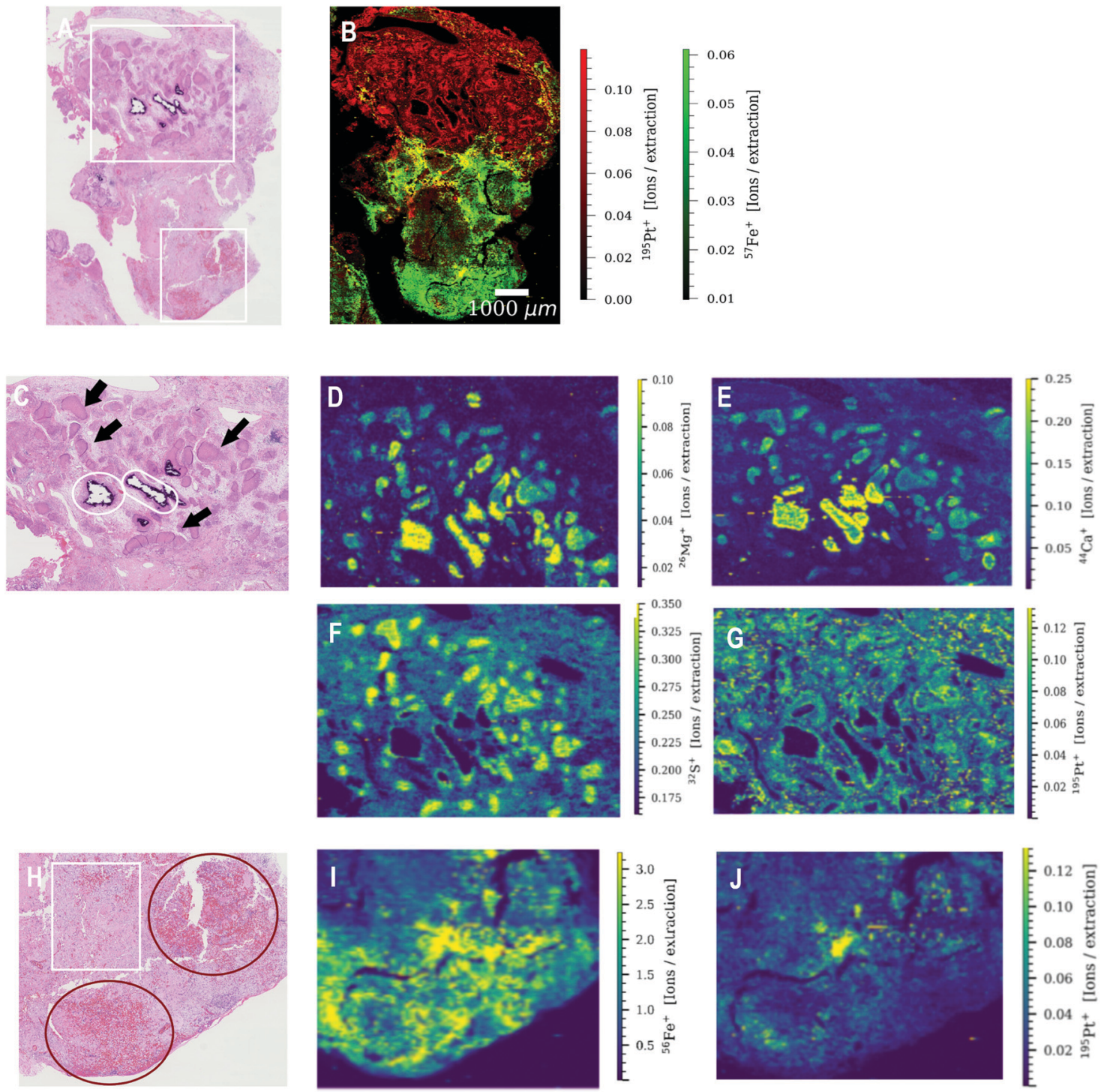

Fig. 3 Correlation of the histology with the elemental distribution pattern obtained by LA-ICP-TOFMS. (A) HE stained slide of a germ cell tumor section of patient 1. Regions of interest (ROIs) are indicated with white squares and zoom-outs of the HE stained slide are shown in (C) and (H). (B) Overlay of ${ }^{195} \mathrm{Pt}^{+}$(red) and ${ }^{57} \mathrm{Fe}^{+}$(green) intensity maps. (C) Areas of necrosis are indicated with black arrows and areas of calcification with white circles. (H) ROIs that are dense in blood vessels are indicated by red circles and the fibrosis scar is indicated by a white square. Corresponding signal intensity maps of (D) ${ }^{26} \mathrm{Mg}^{+},(\mathrm{E}){ }^{44} \mathrm{Ca}^{+},(\mathrm{F}){ }^{32} \mathrm{~S}^{+},(\mathrm{G}){ }^{195} \mathrm{Pt}^{+}$, (I) ${ }^{56} \mathrm{Fe}^{+}$and $(\mathrm{J}){ }^{195} \mathrm{Pt}^{+}$for the ROIs, obtained by LA-ICP-TOFMS. The following laser parameters were used: a square spot size of $20 \mu \mathrm{m}$, a fixed dosage mode of 2 and a repetition rate of $30 \mathrm{~Hz}$. The parallel line scans overlapped one another by $10 \mu \mathrm{m}$.

A similar elemental pattern was also observed by LA-ICPMS for malignant pleural mesothelioma tumor samples of a patient undergoing cisplatin chemotherapy. ${ }^{17}$ In contrast to iron, a correlation of platinum and sulphur signal was observed in the tumor section of patient 1 (Fig. S3, ESI $\dagger$ ), with a low sulphur accumulation in the region of iron enrichment. This correlation can be attributed to the known interaction of cisplatin with proteins or peptides containing thiol groups.

In detail, the germ cell tumor section of patient 1 showed high iron levels and partially enriched platinum concentrations in areas with blood vessels (Fig. $3 \mathrm{H}-\mathrm{J}$ ). An area with fibrosis scar was identified on the HE stained tumor section (Fig. 3H), which correlated with low iron and platinum levels in the LA-ICPTOFMS images (Fig. 3E and F). Pronounced Ca accumulation was found in tissue areas/channels of calcification, which correlates with regions of magnesium and phosphorus enrichment (Fig. 3D-F). In the germ cell tumor sections of patient 2 , highest platinum concentrations were found in glandular structures and in a small part of chondral tissue (Fig. 4A and E). The chondral tissue also exhibited high amounts of phosphorus, iron and gadolinium (Fig. 4A-D). For the second analyzed tumor section of patient 2, an area of necrosis was characterized by high phosphorus and sulphur content and low gadolinium and platinum accumulation (Fig. S2, ESI $\dagger$ )

Regarding correlation of endogenous elements and histology, the influence of sample preparation techniques on qualitative and quantitative elemental distribution pattern in biological samples has to be considered. A comparison study for sample preparation 

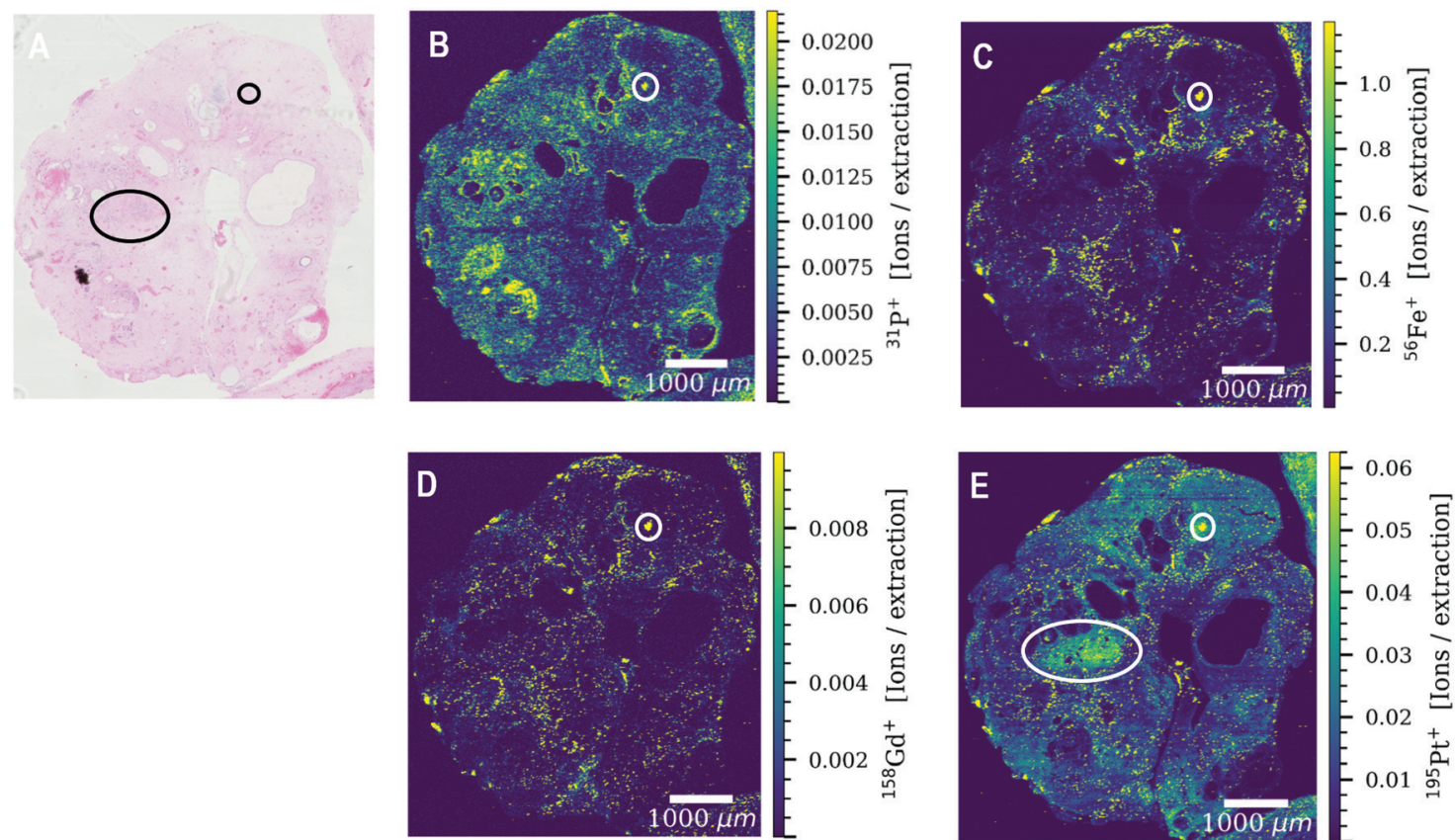

Fig. 4 Correlation of the histology with the elemental distribution pattern obtained by LA-ICP-TOFMS. (A) HE stained slide of a germ cell tumor section of patient 2. Regions of interest (ROIs) are indicated with black circles (glandular structures and small parts of chondral tissue). Signal intensity maps of (B) ${ }^{31} \mathrm{P}^{+},(\mathrm{C}){ }^{56} \mathrm{Fe}^{+},(\mathrm{D}){ }^{158} \mathrm{Gd}^{+}$and $(\mathrm{E}){ }^{195} \mathrm{Pt}^{+}$in a germ cell tumor tissue section of patient 2 obtained by LA-ICP-TOFMS imaging. Small parts of chondral tissue are indicated by a white circle. Glandular structures are indicated in (E) by a white circle. The following laser parameters were used: a square spot size of $20 \mu \mathrm{m}$, fixed dosage mode of 2 and a repetition rate of $30 \mathrm{~Hz}$. The parallel line scans overlapped one another by $10 \mu \mathrm{m}$.

techniques investigated the elemental distributions and concentrations by LA-ICPMS in mice tissue samples after the clinically used FFPE procedure and after cryo-sectioning. ${ }^{30}$ Especially alkaline metals ( $\mathrm{Na}$ and $\mathrm{K}$ ) showed to be severely affected by the sample preparation process of FFPE, resulting in significant losses of these two elements, whereas transition metals showed comparable results to cryo-sectioning. The elements $\mathrm{Na}$ and $\mathrm{K}$ were not used in this study for correlation with the underlying histology. During the sample preparation process, loosely bound elements are prone to be washed out and serious contaminations were observed for $\mathrm{Ca}$ and $\mathrm{Zn}$ and slight contaminations for $\mathrm{Mg} .{ }^{30}$ In our study, however calcium and magnesium distributions corresponded to underlying histological structures and therefore histology should be used as an orthogonal method to LA-ICPMS to evaluate if endogenous elemental distributions in biological samples are conclusive.

\section{Significance of platinum accumulation in central nervous system germ cell tumor}

Primary and metastatic brain malignancies as well as prior CNS radiation can compromise the integrity of the blood-brain barrier, which enables more successful delivery of chemotherapeutic agents to tumors located in the brain. ${ }^{3}$ In our study, the LA-ICP-TOFMS data show a clear platinum accumulation in the different areas of the germ cell tumor tissue, demonstrating that part of cisplatin reached the tumor site, which is also reflected by the therapy response of the patients. In another study, the cerebrospinal fluid (CSF) penetration of cisplatin and carboplatin was determined in non-human primates as surrogate for BBB penetration. The CSF penetration of active drug was $3.7 \%$ for cisplatin and $2.6 \%$ for carboplatin. ${ }^{31}$

\section{Conclusions}

This study shows the potential of LA-ICP-TOFMS imaging for the analysis of elements with biological key functions and the presence of platinum and gadolinium in clinical samples of patients undergoing platinum-based chemotherapy. Clear platinum enrichment was observed in central nervous system germ cell tumor tissue in the brain three weeks after chemotherapy with the anticancer drug cisplatin. Enhanced platinum levels were detected in areas of necrosis, which also showed enrichment in magnesium, sulphur and calcium levels. Highest iron contents were found in areas where blood vessels were present and calcium, phosphorus and magnesium accumulated in areas where the calcification process was taking place. In addition, small traces of gadolinium were found in the tumor sections resulting from a previous MRI of the patients. LA-ICP-TOFMS results reflect observations made by clinical histological screening methods and has the potential to be added to the analytical toolbox for future screening approaches for cisplatin and other metal-based anticancer drugs and drug candidates in (pre-)clinical settings.

\section{Conflicts of interest}

There are no conflicts of interest to declare. 


\section{Acknowledgements}

The authors acknowledge Teledyne Photon machines for financial and technical support. The authors thank Stijn J. M. Van Malderen for software support for HDIP. The authors thank Olga Borovinskaya and Martin Tanner for their help on how to optimize and run the icpTOF 2R ICP-MS instrument and Fred Oestlund for software support for TofPilot.

\section{References}

1 M. E. Echevarria, J. Fangusaro and S. Goldman, Oncologist, 2008, 16(6), 690-699.

2 C. Avendano and J. C. Mendendez, Medicinal Chemistry of Anticancer Drugs. Elsevier Science, Amsterdam, 2008.

3 J. F. Deeken and W. Löscher, Clin. Cancer Res., 2007, 13(6), 1663-1674.

4 D. Pozebon, G. L. Scheffler and V. L. Dressler, J. Anal. At. Spectrom., 2017, 32(5), 890-919.

5 A. Sussulini, J. S. Becker and J. S. Becker, Mass Spectrom. Rev., 2017, 36(1), 47-57.

6 R. F. S. Lee, S. Theiner, A. Meibom, G. Koellensperger, B. K. Keppler and P. J. Dyson, Metallomics, 2017, 9(4), 365-381.

7 I. Moraleja, D. Esteban-Fernández, A. Lázaro, B. Humanes, B. Neumann, A. Tejedor, M. L. Mena, N. Jakubowski and M. M. Gómez-Gómez, Anal. Bioanal. Chem., 2016, 408(9), 2309-2318.

8 T. Van Acker, S. J. M. Van Malderen, M. Van Heerden, J. E. McDuffie, F. Cuyckens and F. Vanhaecke, Anal. Chim. Acta, 2016, 945, 23-30.

9 E. Moreno-Gordaliza, C. Giesen, A. Lázaro, D. EstebanFernández, B. Humanes, B. Cañas, U. Panne, A. Tejedor, N. Jakubowski and M. M. Gómez-Gómez, Anal. Chem., 2011, 83(20), 7933-7940.

10 A. E. Egger, S. Theiner, C. Kornauth, P. Heffeter, W. Berger, B. K. Keppler and C. G. Hartinger, Metallomics, 2014, 6(9), 1616-1625.

11 S. Theiner, E. Schreiber-Brynzak, M. A. Jakupec, M. Galanski, G. Koellensperger and B. K. Keppler, Metallomics, 2016, 8(4), 398-402.

12 S. Theiner, S. J. M. Van Malderen, T. Van Acker, A. Legin, B. K. Keppler, F. Vanhaecke and G. Koellensperger, Anal. Chem., 2017, 89(23), 12641-12645.

13 C. Carlier, B. Laforce, S. J. M. Van Malderen, F. Gremonprez, R. Tucoulou, J. Villanova, O. De Wever, L. Vincze, F. Vanhaecke and W. Ceelen, J. Pharm. Biomed. Anal., 2016, 131, 256-262.
14 O. B. Bauer, O. Hachmöller, O. Borovinskaya, M. Sperling, H.-J. Schurek, G. Ciarimboli and U. Karst, J. Anal. At. Spectrom., 2019, 34(4), 694-701.

15 S. Theiner, C. Kornauth, H. P. Varbanov, M. Galanski, S. Van Schoonhoven, P. Heffeter, W. Berger, A. E. Egger and B. K. Keppler, Metallomics, 2015, 7(8), 1256-1264.

16 M. H. M. Klose, S. Theiner, C. Kornauth, S. M. MeierMenches, P. Heffeter, W. Berger, G. Koellensperger and B. K. Keppler, Metallomics, 2018, 10(3), 388-396.

17 A. E. Egger, C. Kornauth, W. Haslik, S. Hann, S. Theiner, G. Bayer, C. G. Hartinger, B. K. Keppler, U. Pluschnig and R. M. Mader, Metallomics, 2015, 7(3), 508-515.

18 M. Bonta, H. Lohninger, V. Laszlo, B. Hegedus and A. Limbeck, J. Anal. At. Spectrom., 2014, 29(11), 2159-2167.

19 M. Bonta, J. J. Gonzalez, C. D. Quarles, R. E. Russo, B. Hegedus and A. Limbeck, J. Anal. At. Spectrom., 2016, 31(1), 252-258.

20 S. J. M. Van Malderen, A. J. Managh, B. L. Sharp and F. Vanhaecke, J. Anal. At. Spectrom., 2016, 31(2), 423-439.

21 A. Gundlach-Graham and D. Günther, Anal. Bioanal. Chem., 2016, 408(11), 2687-2695.

22 Q. Chang, O. I. Ornatsky, I. Siddiqui, A. Loboda, V. I. Baranov and D. W. Hedley, Cytometry, Part A, 2017, 91(2), 160-169.

23 H. A. O. Wang, D. Grolimund, C. Giesen, C. N. Borca, J. R. H. Shaw-Stewart, B. Bodenmiller and D. Günther, Anal. Chem., 2013, 85(21), 10107-10116.

24 C. Giesen, H. A. O. Wang, D. Schapiro, N. Zivanovic, A. Jacobs, B. Hattendorf, P. J. Schüffler, D. Grolimund, J. M. Buhmann, S. Brandt, Z. Varga, P. J. Wild, D. Günther and B. Bodenmiller, Nat. Methods, 2014, 11, 417.

25 T. Porta Siegel, G. Hamm, J. Bunch, J. Cappell, J. S. Fletcher and K. Schwamborn, Mol. Imaging Biol., 2018, 20(6), 888-901.

26 S. Theiner, A. Schweikert, S. J. M. Van Malderen, A. Schoeberl, S. Neumayer, P. Jilma, A. Peyrl and G. Koellensperger, Anal. Chem., 2019, 91(13), 8207-8212.

27 N. Murata, K. Murata, L. F. Gonzalez-Cuyar and K. R. Maravilla, Magn. Reson. Imaging, 2016, 34(10), 1359-1365.

28 R. Catena, L. M. Montuenga and B. Bodenmiller, J. Pathol., 2018, 244(4), 479-484.

29 R. Catena, A. Özcan, N. Zivanovic and B. Bodenmiller, Cytometry, Part A, 2016, 89(5), 491-497.

30 M. Bonta, S. Török, B. Hegedus, B. Döme and A. Limbeck, Anal. Bioanal. Chem., 2017, 409(7), 1805-1814.

31 S. S. Jacobs, E. Fox, C. Dennie, L. B. Morgan, C. L. McCully and F. M. Balis, Clin. Cancer Res., 2005, 11(4), 1669-1674. 